\title{
IMPACT OF ROCKET EXHAUST PLUMES ON ATMOSPHERIC COMPOSITION AND CLIMATE - AN OVERVIEW
}

\author{
Ch. Voigt ${ }^{1,2}$, U. Schumann ${ }^{1}$, K. Graf ${ }^{1}$, \\ and K.-D. Gottschaldt ${ }^{1}$ \\ ${ }^{1}$ Deutsches Zentrum für Luft- und Raumfahrt (DLR) \\ Institut für Physik der Atmosphäre \\ Oberpfaffenhofen, Wessling 82234, Germany \\ ${ }^{2}$ Johannes-Gutenberg-Universität Mainz \\ Institut für Physik der Atmosphäre \\ 21 Johannes-Joachim-Becher-Weg, Mainz 55099, Germany
}

\begin{abstract}
Rockets are the only direct anthropogenic emission sources into the upper atmosphere. Gaseous rocket emissions include $\mathrm{CO}, \mathrm{N}_{2}, \mathrm{H}_{2}, \mathrm{H}_{2} \mathrm{O}$, and $\mathrm{CO}_{2}$, while solid rocket motors (SRM) additionally inject significant amounts of aluminum oxide $\left(\mathrm{Al}_{2} \mathrm{O}_{3}\right)$ particles and gaseous chlorine species into the atmosphere. These emissions strongly perturb local atmospheric trace gas and aerosol distributions. Here, previous aircraft measurements in various rocket exhaust plumes including several large space shuttle launch vehicles are compiled. The observed changes of the lower stratospheric composition in the near field are summarized. The injection of chlorine species and particles into the stratosphere can lead to ozone loss in rocket exhaust plumes. Local observations are compared with global model simulations of the effects of rocket emissions on stratospheric ozone concentrations. Large uncertainties remain concerning individual ozone loss reaction rates and the impact of small-scale plume effects on global chemistry. Further, remote sensing data from satellite indicate that rocket exhaust plumes regionally increase iron and water vapor concentrations in the mesosphere potentially leading to the formation of mesospheric clouds at 80 - to 90 -kilometer altitude. These satellite observations are summarized and the rocket emission inventory is compared with other natural and anthropogenic sources to the stratosphere such as volcanism, meteoritic material, and aviation.
\end{abstract}




\section{INTRODUCTION}

Although rocket exhaust plumes currently represent only a tiny fraction of the total anthropogenic emissions into the atmosphere, their atmospheric effects should be addressed with caution. Space traffic, in particular, space tourism, is expected to increase in coming decades [1]; hence, it is important to investigate local and global perturbations of the atmospheric composition by rocket exhaust emissions and to understand the atmospheric processes occurring in the plumes at all scales. Near the launch site, rocket launches potentially have a strong and short term impact on air quality, which remains to be quantified in detail. While atmospheric composition changes related to rocket emissions may be of transient nature in the troposphere, long-term effects are expected in the stratosphere, particularly, affecting the stratospheric ozone budget [2].

The atmospheric effects of rocket emissions depend on the type of propellant. Solid rocket motors consisting of aluminum fuel and an ammonium perchlorate $\left(\mathrm{NH}_{4} \mathrm{ClO}_{4}\right)$ oxidizer represent only a fraction of the total rocket emission inventory. Solid rocket motors are often combined with cryogenic rocket engines with liquid oxygen and liquid hydrogen $\left(\mathrm{LOx} / \mathrm{H}_{2}\right)$ compartments to increase thrust. For example, this engine type powers the expendable rocket launch system Ariane 5. In addition, a liquid oxygen/kerosene ( $\mathrm{LOx} /$ kerosene) booster rocket system is commonly used in space industry, e.g., for the Soyuz launch vehicle.

Here, the previous aircraft observations of rocket exhaust plumes from different rocket engine types in the lowest stratosphere are summarized. These measurements are important to characterize mixing and to quantify small-scale plume processes required to model the global impact of rocket emissions on the atmospheric composition. The aircraft measurements and global model simulations of the impact of rocket emissions on local and global stratospheric ozone levels are further discussed. The satellite observations of enhanced mesospheric cloud formation above 80-kilometer altitude related to rocket launches are compiled and the rocket emissions are compared with other emission inventories such as volcanoes, meteoritic input, and aviation.

\section{DETECTION OF ROCKET EXHAUST PLUMES IN THE STRATOSPHERE}

While direct measurements of rocket emissions from European launch vehicles are missing, the exhaust plumes from several space shuttle launch vehicles, a Titan IV, an Athena II, an Atlas II, and a Delta II rocket have been probed previously with in situ instruments on the NASA WB57 high altitude research aircraft. These observations of rocket exhaust plumes are summarized in Table 1. 
Table 1 Previous in situ observations of exhaust plumes from different rockets: the rocket and motor type, the site of observation Cape Canaveral (CC, $28 \mathrm{~N}, 80 \mathrm{~W})$ and Vandenberg Airforce Base (VA, 34 N, $120 \mathrm{~W}$ ), the altitude of observation and the plume age, the date of the rocket launch and the species on which published results exist

\begin{tabular}{|c|c|c|c|c|c|c|}
\hline $\begin{array}{l}\text { Rocket } \\
\text { type }\end{array}$ & $\begin{array}{l}\text { Motor } \\
\text { type }\end{array}$ & Site & $\begin{array}{l}\text { Altitude, } \\
\text { km }\end{array}$ & $\begin{array}{l}\text { Plume } \\
\text { age } \\
\text { min } \\
\end{array}$ & $\begin{array}{l}\text { Published results } \\
\text { on measured species }\end{array}$ & Date \\
\hline Titan IV & $\mathrm{SRM}$ & $\mathrm{CC}$ & 19.8 & 29 & $\begin{array}{c}\mathrm{O}_{3}, \mathrm{Cl}_{2}, \\
\operatorname{PSD}(0.01-4 \mu \mathrm{m}), \mathrm{cn}\end{array}$ & $\begin{array}{r}4 / 24 / 1996 \\
12 / 20 / 1996\end{array}$ \\
\hline $\begin{array}{l}\text { Space shuttle } \\
\text { STS83/STS85 }\end{array}$ & SRM & $\mathrm{CC}$ & $17-19.5$ & $5-125$ & PSD $(0.01-4 \mu \mathrm{m}), \mathrm{cn}$ & $\begin{array}{l}4 / 04 / 1997 \\
6 / 08 / 1997 \\
\end{array}$ \\
\hline Delta II & $\begin{array}{c}\text { SRM/ } \\
\text { (LOx/ } \\
\text { kerosene) }\end{array}$ & VA & $\begin{array}{l}18-19.4 \\
11-12\end{array}$ & 12,39 & $\begin{array}{c}\mathrm{O}_{3}, \mathrm{ClO}, \mathrm{CO}_{2} \\
\mathrm{CH}_{4}, \mathrm{cn}, \mathrm{PSD}, \mathrm{cn}\end{array}$ & $\begin{array}{r}11 / 07 / 1996 \\
5 / 17 / 1998 \\
4 / 15 / 1999 \\
\end{array}$ \\
\hline Athena II & $\mathrm{SRM}$ & VA & $16-19$ & $4-26$ & $\begin{array}{c}\mathrm{ClO}, \mathrm{CO}_{2}, \mathrm{H}_{2} \mathrm{O}, \mathrm{NO}_{y}, \\
\mathrm{HNO}_{3}, \text { Part. comp. } \\
\text { PSD, cn }\end{array}$ & $9 / 24 / 1999$ \\
\hline Atlas IIAS & $\begin{array}{c}\mathrm{SRM} / \\
(\mathrm{LOx} / \\
\text { kerosene })\end{array}$ & $\mathrm{CC}$ & 19 & - & $\mathrm{CO}_{2}, \mathrm{PSD}, \mathrm{cn}$ & $4 / 12 / 1999$ \\
\hline $\begin{array}{l}\text { Space shuttle } \\
\text { STS106 }\end{array}$ & $\begin{array}{c}\mathrm{SRM} / \\
\left(\mathrm{LOx} / \mathrm{H}_{2}\right)\end{array}$ & $\mathrm{CC}$ & - & $5-90$ & Part. comp. & $9 / 08 / 2000$ \\
\hline
\end{tabular}

In 1996 and 1997, aerosol size distributions of rocket exhaust plumes from two large SRM space shuttles and a Titan IV rocket have been detected at altitudes between 17.5 and $19 \mathrm{~km}$ with a real time particle counter and a grab tank sampling system onboard the WB57 aircraft [3]. Particle number concentrations of several hundred per cubic centimeter of $\mathrm{Al}_{2} \mathrm{O}_{3}$ particles in the size range between 0.01 and $4 \mu \mathrm{m}$ have been observed in the 5 -minute old stratospheric exhaust plumes. The rocket exhaust plumes exhibited a tri-modal particle size distribution with modes near $0.005,0.1$, and $2 \mu \mathrm{m}$. While the long-lived atmospherically relevant smallest mode contained less than $0.1 \%$ of the alumina mass, more than $99 \%$ of the particle mass was concentrated in the largest mode. Aerosol concentrations of few hundred per cubic centimeter have been measured in the stratospheric exhaust plume of a Delta II rocket powered by a combination of a solid $\left(\mathrm{NH}_{4} \mathrm{ClO}_{4} / \mathrm{Al}\right)$ and a liquid (LOx/kerosene) propulsion system [4]. This plume has been intercepted with the WB57 aircraft six times at plume ages between $12 \mathrm{~min}$ and $1 \mathrm{~h}$. High amounts of reactive chlorine in the form of chlorine monoxide $(\mathrm{ClO})$ of up to $45 \mathrm{nmol} / \mathrm{mol}$ initially decreased with plume age while ozone loss increased. Complete ozone destruction was observed in the 39-minute 
old rocket exhaust plume. Probably, the local ozone holes were induced by gas phase (and heterogeneous) reactions with chlorine species.

In addition, the stratospheric exhaust plume of a small Athena II SRM has been probed near 18-kilometer altitude at plume ages between 4 and $26 \min$ [5]. The plume showed high alumina particle abundances near 10,000 per $\mathrm{cm}^{3}$ in the size range between 0.004 and $1.2 \mu \mathrm{m}$. About $8 \%$ of the total mass $(37 \%$ of the total surface area) was contained in the submicron particles, significantly more than observed in previous studies [3]. Small particles most influence the stratospheric impact of rocket emissions on ozone due to their longer atmospheric lifetime. Hence, ozone loss due to gas phase chlorine chemistry alone may be increased by heterogeneous reactions on SRM alumina particles [5].

The same Athena II SRM plume has been sampled with a single particle aerosol mass spectrometer [6] onboard the WB57. More than 2300 particles from the Athena II SRM plume and a space shuttle plume were analyzed. The plume particles exhibited variable compositions and also contained trace components of the alumina fuel and the combustion catalyst. For example, chlorine from the oxidizer, iron and elemental carbon were found in the Athena II rocket plume and nitrate, phosphate and water were detected in the space shuttle plume particles [6]. These observations add new uncertainties to the heterogeneous chlorine chemistry in the plume as reaction rates on coated alumina particles are not known. Laboratory measurements would be required to investigate reactions rates of chlorine species on coated alumina particles.

Measurements of reactive nitrogen $\left(\mathrm{NO}_{y}\right)$ and nitric acid $\left(\mathrm{HNO}_{3}\right)$ in the Athena II SRM plume [7] showed $\mathrm{NO}_{y}$ mixing ratios above $100 \mathrm{nmol} / \mathrm{mol}$ in the less than 30-minute old rocket plume. Nitric acid mixing ratios larger than $50 \mathrm{nmol} / \mathrm{mol}$ indicated that $\mathrm{HNO}_{3}$ was a significant plume component, most probably formed by the heterogeneous reaction between chlorine nitrate $\left(\mathrm{ClONO}_{2}\right)$ and hydrochloric acid $(\mathrm{HCl})$ on the emitted alumina particles. The formation of $\mathrm{HNO}_{3}$ in the young rocket exhaust plumes remains to be quantified using boxmodel simulations including heterogeneous chemistry on particles.

Observed enhanced nitric acid concentrations combined with temperatures below $215 \mathrm{~K}$ may favour the formation of nitric acid trihydrate (NAT) particles in rocket exhaust plumes as suggested by Gates et al. [8]. The NAT nucleation on ice has frequently been observed in polar stratospheric clouds [9]. A similar process may occur in stratospheric rocket wakes, as inferred from measurements in the exhaust plumes from an Atlas II, a Delta II, and an Athena II rocket. The formation of NAT particles in rocket plumes may extend and enhance ozone loss, because nitrogen oxides, which are required to passivate active chlorine species, would be bound in the NAT particles.

Summarized, in situ measurements in rocket exhaust plumes are rare. Most aircraft measurements presented above have been performed at altitudes between 16 and $19 \mathrm{~km}$ in the lowest stratosphere in rocket exhaust plumes with ages less than $2 \mathrm{~h}[3-9]$. More observations in very young exhaust plumes are required 
to validate rocket engine models and to characterize nonlinear mixing processes, concentration gradients within the plumes, afterburning, and small scale plume effects. Also, the applicability of rocket emission inventories to the global scale and global modeling remains to be tested. Global and regional scale models would particularly profit from in situ observations in older plumes, representing the effective emissions on the respective grid scales (tens or even hundreds of kilometers).

\section{LOCAL, REGIONAL, AND GLOBAL STRATOSPHERIC OZONE LOSS CAUSED BY ROCKET EMISSIONS}

Local ozone loss and ozone mini holes have been observed in young rocket exhaust plumes during daytime [4]. Here, the simulations of the impact of rocket emissions on regional and global ozone levels are summarized. Two- (2D) and three-dimensional (3D) atmospheric chemistry transport models (CTM) were used to follow the buildup of exhaust products and their perturbation to stratospheric ozone levels [10]. These models include the 2D chemistry AER model [11], the GSFC model [12], and the 3D GISS model for chemical tracers [13]. The three CTM derived chlorine enhancements of less than $0.6 \%$ above the background due to emissions from a fleet of 9 space shuttles and 3 Titan rockets representative for the 1990 fleet [10]. Gas phase processes including ozone loss by the $\mathrm{ClO}$ dimer catalytic cycle led to a maximum ozone loss of $0.12 \%$ in the northern mid-latitude upper stratosphere near 40-kilometer altitude, while the total ozone column would be reduced by significantly less than $0.1 \%$.

In addition to gas phase chemistry alone, heterogeneous ozone loss on the stratospheric sulfate aerosol layer and polar stratospheric clouds has been calculated with the 2D photochemistry and transport GSFC model for the same launch scenario [14]. The model calculated annually averaged global total ozone decreases of $0.006 \%$ related to gas phase chemistry only, and of $0.014 \%$ including gas phase and heterogeneous reactions on sulphate aerosol and polar stratospheric clouds. Regional effects are significantly larger. The same model has been used to also derive the effects of heterogeneous chlorine activation directly on alumina particles emitted by SRM using historical launch rates of space shuttles and Titan III and Titan IV rockets [15]. Results from the time-dependent steadystate model showed an average global total ozone decrease of $0.025 \%$ for the year 1997. About one third of this change resulted from heterogeneous reactions on alumina particles emitted by SRM. Still recent in situ particle measurements show that the emitted alumina particles can be coated with emission products from the combustion catalyst and the oxidizer, imposing a new uncertainty on those simulations. 
The atmospheric, impact of launching the Ariane 5 rocket has been calculated with a $2 \mathrm{D}$ chemical-transport model and short-term as well as long-term atmospheric responses were considered [16]. In addition, the release of various partitionings of chlorine species was addressed. Ozone loss caused by a fleet of 10 Ariane 5 rockets was less than $0.1 \%$ locally and globally. Jones et al. [16] conclude that the release of alumina particles from 10 Ariane 5 launches per year may increase the stratospheric aerosol layer by about $1 \%$.

Ozone loss caused by $\mathrm{NO}$ and $\mathrm{H}_{2} \mathrm{O}$ emissions from hydrazine-fueled rockets has been calculated with plume and global atmosphere models [17]. Hydrazinefueled rockets such as Proton may account for about one third of all stratospheric rocket emissions comparable in mass to solid-fueled rocket emissions. While the maximum calculated local and time-dependent ozone loss was $21 \%$ at 44-kilometer altitude due to the catalytic NO cycle, the steady state global ozone loss from 10 Proton launches annually is $0.012 \%$; thus, hydrazine-fueled rockets contribute significantly less effective to ozone destruction than solid-fueled rockets.

The impact of a future fleet of 1000 suborbital hybrid rocket engines burning solid hydrocarbon fuels potentially used for commercial purposes has been investigated recently [18]. These potential emissions would create a persistent layer of black carbon particles in the northern hemispheric stratosphere leading to changes in the global atmospheric circulation and, hence, in ozone and temperature distributions.

Results from all model simulations [10-18] show a global annual ozone loss of significantly less than $0.1 \%$ caused by rocket emissions considering different gas phase and heterogeneous ozone loss processes. However, regional effects are more pronounced and can be in a few percent range. Complete ozone destruction has been observed on local plume scales.

Main uncertainties include reactions on other particle surfaces as detected by aerosol mass spectrometry [6]. In addition, the gas phase and heterogeneous chemistry occurring during afterburning and in young plumes requires further attention. Very little is known on small-scale plume effects, their mixing, and the concentration gradients caused by turbulent and laminar mixing within the plume and of the plume with the atmosphere. Particularly, chemistry and effects spanning the nozzle exit conditions to the local, regional and global scale require further investigations.

\section{MESOSPHERIC CLOUD FORMATION CAUSED BY ROCKET EMISSIONS}

Several studies relate the detection of enhanced water vapor layers and of ice clouds in the mesosphere at altitudes above $80 \mathrm{~km}$ to the launch of space ve- 
hicles. Direct evidence of a mesospheric water vapor change caused by rocket emissions has been obtained from water vapor radiance data from the Sounding of the Atmosphere with Broadband Emission Radiometry (SABER) instrument on the Thermosphere Ionosphere Mesosphere Energetics and Dynamics (TIMED) satellite [19]. Over a 10-month period in 2002, the radiometer detected radiance enhancements between 90 and $130 \mathrm{~km}$ altitude which could be related in time and location to launches from space shuttle launch vehicles and from liquidfueled rockets. About $40 \%$ of the total liquid-fueled rocket launches and all space shuttle launches in that period were identified in the radiance data and led to enhanced water vapor mixing ratios in the mesosphere.

Another evidence of the impact of rocket exhaust plumes on the mesospheric composition is the observation of a layer with enhanced $\mathrm{OH}$ concentrations with the Middle Atmosphere High Resolution Spectrograph Investigation (MAHRSI) instrument in the payload of the space shuttle Discovery (STS-85) in 1997 [20]. The Arctic mesospheric $\mathrm{OH}$ plume has been observed one day after the space shuttle launch at altitudes above $85 \mathrm{~km}$. At these altitudes, $\mathrm{OH}$ is produced predominantly by the photolysis of water vapor; hence, $\mathrm{OH}$ can be regarded as an indicator for water vapor. One week later, a polar mesospheric cloud (PMC) has been detected between $70 \mathrm{~N}$ and $75 \mathrm{~N}$ with the CRyogenic Infrared Spectrometers and Telescopes for the Atmosphere-Shuttle PAllet Satellite (CRISTA-SPAS) instrument in the Discovery payload. The inferred ice water content of the cloud was of the same order of magnitude as the water vapor mixing ratio injected by the space shuttle into the mesosphere (about $3.5 \mu \mathrm{mol} / \mathrm{mol}$ ). The location of the PMC was linked to the site of the initial water vapor enhancement caused by the space shuttle exhaust using trajectory calculations.

In addition, the transport of a space shuttle exhaust plume to the southern hemisphere has been observed by the Global Ultraviolet Imager (GUVI) instrument on the TIMED satellite [21]. The instrument detects mesospheric water vapor using scattered solar Lyman- $\alpha$ radiation. The water vapor plume of the Columbia space shuttle (STS-107) launched from Kennedy Space Center in January 2003 was detected over 2 days. Initially, it spread out and moved north-east and after one day, it changed to southern directions even reaching $35 \mathrm{~S}$. A ground-based light detection and ranging (Lidar) system in Rothera detected enhanced PMC occurrence above Antarctica a few days after the space shuttle launch. These observations suggest a global impact of rocket launches in the mesosphere. The Lidar also observed enhanced iron layers near 112kilometer altitude after the Columbia launch with iron concentrations reaching $1.5 \cdot 10^{4} \mathrm{~cm}^{-3}$. Probably the iron had ablated from the shuttle's main engines as no natural source of neutral iron is known at altitudes above $100 \mathrm{~km}$.

Lidar, Radar, and optical observations have also been performed in the northern hemisphere (Alaska) in the polar summer mesosphere shortly after the launch of the space shuttle STS-118 in 2007 [22]. Such a single space shuttle launch may lead to about $0.3 \mathrm{Gg}$ of water vapor in altitudes between 100 and $110 \mathrm{~km}$ [22]. 
An intense mesospheric cloud has been detected 3 days after the STS-118 launch. Similar to previous observations, the space shuttle launch has been followed by enhanced polar mesospheric cloud formation and by the buildup of iron layers. In this case, the iron layer density increased by a factor of 20 compared to background levels. In addition, the radar recorded polar mesospheric summer echoes (PMSE) related to this event. The PMSE are probably related to plasma interactions in mesospheric clouds, involving dust. Rocket emissions interfere with such a monitoring. Hence, communication might also be affected by such electromagnetic phenomena.

Summarized, recent observations [19-22] give evidence for enhanced water vapor layers, mesospheric cloud formation, and iron occurrence in the mesosphere at altitudes above $80 \mathrm{~km}$ related to rocket launches. These enhancements do not only have a local character, but soon spread out and may acquire a regional or even hemispheric character. Still potential effects on mesospheric transport pathways and on mesospheric chemistry as well as climate effects remain elusive. However, mesospheric temperatures might be more sensitive to climate change than tropospheric temperatures [23]. Thus, observations of changes in polar mesospheric summer echoes which might be useful for monitoring global change have to be related to the launch of space shuttles and other rockets.

\section{COMPARISON OF THE ROCKET EMISSION INVENTORY TO OTHER ANTHROPOGENIC OR NATURAL SOURCES}

After having compiled previous observations and model simulations of the atmospheric impact of rocket launch vehicles, let now investigate the rocket emission inventory and compare rocket emissions to stratospheric inputs from other sources such as aviation, volcanoes, and meteoritic material. The propulsion systems of the present day rocket fleet do not contain significant amounts of sulphur; thus, the contribution of rocket emissions to the stratospheric sulphate aerosol layer is negligible. This estimate is confirmed by Lidar observations of the evolution of the stratospheric aerosol layer [24], where no impact of rocket launches can be identified. In addition, model simulations [16] show that the enhancement of the sulphate aerosol layer by alumina particles released from 10 Ariane $5 \mathrm{SRM}$ per year is the modest in the range of $1 \%$ of the stratospheric sulphate aerosol mass.

Meteorites provide another source of particles into the stratosphere. About 8 to $30 \mathrm{Gg}$ per year of meteoritic material enters the atmosphere [25]. A large fraction (about $60 \%$ ) of the meteoritic mass influx in the atmosphere ablates at altitudes above $80 \mathrm{~km}$ due to frictional heating. The ablation products recondense, coagulate in the mesosphere and form nanometer-sized smoke particles. 
The meteoritic smoke particles are then transported with the atmospheric circulation. They sediment down, and most of them likely enter the stratosphere over the winter pole. There, the meteoritic particles remain for more than a year, they become well-mixed and are partly incorporated into the stratospheric sulfate aerosol $[25,26]$.

Averaged over the years 2000 to 2002, the total rocket propellant emission from a fleet of space shuttles, Titan IV, Proton, Long March, Ariane 5, Soyuz, Zenit, and smaller rocket launch vehicles has been calculated to amount to $\sim 30 \mathrm{Gg}$ per year of which about $9 \mathrm{Gg}$ per year are emitted into the stratosphere [13]. While the total amount of rocket emissions into the stratosphere is of similar magnitude as the meteoric influx, the particulate alumina fraction of the rocket emissions in stratosphere is about one third of the total emissions and amounts to $\sim 3 \mathrm{Gg}$ annually.

A rocket fleet of six Ariane 5 launch vehicles, using SRM and cryogenic $\mathrm{LOx} / \mathrm{H}_{2}$ propellants, two Vega rockets with SRM and two Soyuz with a LOx/ kerosene propellant would release about $5 \mathrm{Gg} \mathrm{CO}_{2}$ into the atmosphere, and only a small fraction of this is released into the troposphere and the lower stratosphere. Even taking into account the total emissions from the global rocket fleet, the rocket $\mathrm{CO}_{2}$ emissions are by 4 to 5 orders of magnitude lower than $\mathrm{CO}_{2}$ emissions from aviation, which lie in the range of 600 to $700 \mathrm{Tg}$ per year in 2005 .

Similar order of magnitude estimates can be performed for water vapor emissions from a rocket fleet. An assumed rocket fleet of six Ariane 5, two Vega, and two Soyuz emits about $2 \mathrm{Gg} \mathrm{H}_{2} \mathrm{O}$ per year into the stratosphere, which is about 4 orders of magnitude lower than water formation by methane in the stratosphere of $45 \mathrm{Tg}$ annually. Another example, water vapor emissions by aviation contribute about $250 \mathrm{Tg}$ per year to the global water cycle in the troposphere and stratosphere.

Hence, while the stratospheric water budget is not significantly perturbed by water emissions from rockets, significant enhancements of water vapor levels have been detected regionally and on hemispheric scales in the mesosphere often collocated with enhanced mesospheric cloud formation. A significant fraction of PMC formation may be caused by rocket emissions and Stevens et al. [21] found that one single space shuttle launch did change the annual 2002-2003 PMC mass between $65^{\circ} \mathrm{S}$ and $79^{\circ} \mathrm{S}$ by $10 \%$ to $20 \%$.

\section{DISCUSSION AND OUTLOOK}

Summarized, strong local and regional perturbations of lower stratospheric trace gas and particle fields have been observed by in situ instruments on aircraft after rocket launches. Most aircraft measurements of rocket plumes have been performed at altitudes between 16 and $19 \mathrm{~km}$ in the lowest stratosphere and 
only one observation exists between 11- and 12-kilometer altitude. Additional lower altitude observations can show different results as emissions are injected deeper into the troposphere. The observed plumes had ages between $4 \mathrm{~min}$

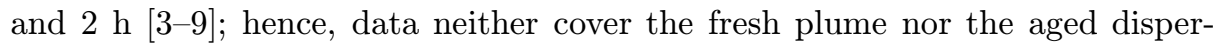
sion regime. New in situ measurements could help to validate afterburning and early plume processes under real atmospheric conditions. Plume heterogeneity and small-scale plume evolution are not considered at all and could be addressed with statistical methods, provided the observational data set was large enough. Some of the in plume variances result from different mixing processes in different parts of the plume and may depend on the relative position to the plume center. Hence, observations will have to be evaluated statistically and with respect to the plume center. In addition, different nonlinear mixing processes occur during plume ageing in the individual exhaust regimes (jet regime, early and aged dispersion regime). Dilution could be investigated using observations of a nonreactive exhaust tracer extending over a long time period of plume evolution. Thereby, different inlet dilution systems will be required to observe the plume mixing ratios in both the very young and the aged plume regime.

All rocket exhaust plume observations were performed between 1996 and 2000 by NASA from Cape Canaveral, Florida $\left(28^{\circ} 33^{\prime} \mathrm{N}, 80^{\circ} 18^{\prime} \mathrm{W}\right)$ or from Vandenberg Air Force Base, CA $\left(34^{\circ} 48^{\prime} \mathrm{N}, 120^{\circ} 37^{\prime} \mathrm{W}\right)$ in the subtropics. Transport patterns, exchange of air between the stratosphere and the troposphere as well as the lifetime of individual species change in different regions of the atmosphere. In general, air is lifted in the tropical troposphere transported to the poles by the Brewer Dobson circulation in the stratosphere and there it descends and reenters the troposphere. Hence, the atmospheric impact and transport of rocket emissions in tropical, mid-latitude, or polar regions remain to be quantified.

In addition, in situ observations from other space launch vehicles are missing. While exhaust plumes from a Titan IV, an Athena II, an Atlas II, and a Delta II rocket and several space shuttle launch vehicles were performed from Cape Canaveral or from Vandenberg Air Force Base, such measurements do not exist from those rockets launched at Eurasian launch sites. These observations are urgently needed to validate box- and large-eddy simulation (LES) models of the young plume and to understand the impact of plume processes on the local and global atmospheric chemistry.

Chlorine and particulate emissions from rocket launch vehicles cause complete ozone destruction in the young exhaust plume and potentially lead to a global total ozone loss smaller than $1 \%$. Still, the ozone loss mechanism strongly depends on particle composition and surface. In the ageing plume, the emitted particles undergo various transformation processes, they may get activated, gain a coating, accumulate and agglomerate, mix with ambient aerosol, take up trace gases and sediment out. Smaller particles have a larger surface to volume ratio than larger particles. In addition, larger particles sediment out faster; as a result, 
larger particles activate chlorine less efficiently than small particles of the same total mass.

Few observations of the particle size distribution in young plumes exist, and there is also a unique observation of aerosol composition from an aerosol mass spectrometer [6]. However, these observations reveal that observed particle composition and surface activity is strongly different from that being used in global models; hence, the estimates on ozone loss are highly uncertain. Therefore, insufficient knowledge on specific variables in ozone destruction such as heterogeneous chlorine chemistry, alumina particle composition, particle coating and reactivity, the use of other propellants renders the final conclusion on global ozone loss open. Atmospheric observations could be complemented with laboratory measurements that investigate the reaction rates on coated alumina.

In particular, the plume conditions at the nozzle exit and the chemistry in the afterburning process remain to be quantified. Further, the extrapolation of plume processes to the global scale requires additional scientific work. Mixing within the plume and at its boundary and related nonlinear chemical effects are not well characterized. However, bridging the scales in modeling from nozzle exit emissions to the grid size of global models is a major challenge. This task will certainly require a hierarchy of different models, possibly including chemical box models, LES models with detailed chemistry, or different instances of regional models nested in a global model. Various approaches were discussed in [27]. Additional in situ measurements of rocket exhaust plumes could help to quantify processes on the plume scale and to validate those models. Measurements of rocket plumes at low altitudes do not exist, and observations in fresh $(<4 \mathrm{~min})$ and older $(>1 \mathrm{~h})$ rocket exhaust plumes could give more insight in the plume evolution. Global and regional scale models would particularly profit from in situ observations in older plumes, representing the effective emissions on the respective grid scales (tens or even hundreds of kilometers).

In addition, such observations could help to establish parameterizations to calculate ozone loss on particles and to evaluate the relative importance of ozone depletion caused by different types of rocket propellants. Multimodel comparisons with standardized configurations - specifically designed for rocket emission effects - would also be very desirable to identify uncertainties and particular weaknesses of the individual models.

Besides of the effects on ozone, rocket aerosol and water emissions above the troposphere also affect the global radiation budget and mesospheric clouds. Electromagnetic effects (i. e., PMSE) in mesospheric clouds are not well understood yet. The detailed evaluation of these effects on the global scale will require models that include all relevant processes, from the Earth's surface to the mesosphere. The development of such models has just begun and more observations will be needed to develop and tune needed parameterizations and to finally validate the models. 
While the present day ozone loss caused by rocket emissions may be small, future ozone changes may not be; particularly, when considering increases in the rocket launch rate caused by space tourism or by geoengineering measures in space [2]. In addition, rocket induced ozone loss might become relatively more important in near future when the anthropogenic stratospheric halogen loading decreases due to the Montreal protocol.

\section{REFERENCES}

1. Sanderson, K. 2010. Science lines up for seat to space. Nature. Special Report 463:716-17.

2. Ross, M. N., D. Toohey, M. Peinemann, and P. Ross. 2010. Limits on the space launch market related to stratospheric ozone depletion. Astropolitics 7:50-82.

3. Ross, M. N., P. D. Whitefield, D. E. Hagen, and A. R. Hopkins. 1999. In situ measurement of the aerosol size distribution in stratospheric solid rocket motor exhaust plumes. Geophys. Res. Lett. 26:7-13.

4. Ross, M. N., D. W. Toohey, W. T. Rawlins, E. C. Richard, K. K. Kelly, A. F. Tuck, M. H. Proffistt, D.E. Hagen, A. R. Hopkins, P.D. Whitefield, J. R. Benbrook, and W.R. Sheldon. 2000. Observation of stratospheric ozone depletion associated with Delta II rocket emissions. Geophys. Res. Lett. 27:2209-12. doi:10.1029/1999GL011159.

5. Schmid, O., J. M. Reeves, J. C. Wilson, C. Wiedinmyer, C. A. Brock, D. W. Toohey, L. M. Avallone, A. M. Gates, and M. N. Ross. 2003. Size-resolved particle emission indices in the stratospheric plume of an Athena II rocket. J. Geophys. Res. 108:4250-56. doi:10.1029/2002JD002486.

6. Cziczo, D. J., D. M. Murphy, D. S. Thomson, and M. N. Ross. 2002. Composition of individual particles in the wakes of an Athena II rocket and the space shuttle. Geophys. Res. Lett. 29:2047-51. doi:10.1029/2002GL015991.

7. Popp, P. J., B. A. Ridley, J. A. Neuman, L. M. Avallone, D. W. Toohey, P. F. Zittel, O. Schmid, R. L. Herman, R. S. Gao, M. J. Northway, J. C. Holecek, D. W. Fahey, T. L. Thompson, K. K. Kelly, J. G. Walega, F. E. Grahek, J. C. Wilson, M. N. Ross, and M. Y. Danilin. 2002. The emission and chemistry of reactive nitrogen species in the plume of an Athena II solid-fuel rocket motor. Geophys. Res. Lett. 29(18):188791. doi:10.1029/2002GL015197.

8. Gates, A.M., L.M. Avallone, D.W. Toohey, A.P. Rutter, P.D. Whitefield, D. E. Hagen, A. Raymond Hopkins, M. N. Ross, P.F. Zittel, T. L. Thompson, R. L. Herman, and R. R. Friedl. 2002. In situ measurements of carbon dioxide, $0.37-4.0 \mu \mathrm{m}$ particles, and water vapour in the stratospheric plumes of small rockets. J. Geophys. Res. 107:4649-56. doi:10.1029/2002JD002121.

9. Voigt, C., J. Schreiner, A. Kohlmann, P. Zink, K. Mauersberger, N. Larsen, T. Deshler, C. Kröger, J. Rosen, A. Adriani, F. Cairo, G. Di Donfrancesco, 
M. Viterbini, J. Ovarlez, H. Ovarlez, C. David, and A. Dörnbrack. 2000. Nitric acid trihydrate (NAT) in polar stratospheric clouds. Science 290:1756-58.

10. Prather, M., M. M. Garcia, A.R. Douglass, C.H. Jackman, M. K.W. Ko, and N.D. Sze. 1990. The space shuttle's impact on the stratosphere. J. Geophys. Res. 95:18583-90.

11. Ko, M. K. W., K. K. Tung, D. K. Weisenstein, and N.D. Sze. 1985. A zonal mean model of stratospheric tracer transport in isentropic coordinates: Numerical simulations for nitrous acid and nitric acid. J. Geophys. Res. 90:2313-21.

12. Douglass, A., C. H. Jackman, and R. S. Stolarski. 1989. Comparison of model results transporting the odd nitrogen family with results transporting separate odd nitrogen species. J. Geophys. Res. 94:9862-72.

13. Prather, M., M. M. Gates, R. Suozzo, and D. Rind. 1990. Global impact of the Antarctic ozone hole. J. Geophys. Res. 95:3449-71.

14. Jackman, C., D. Considine, and E. Fleming. 1996. Space shuttle's impact on the stratosphere: An update. J. Geophys. Res. 101(D7). doi:10.1029/96JD00577.

15. Jackman, C. H., D. B. Considine, and E. L. Fleming. 1998. A global modeling study of solid rocket aluminum oxide emission effects on stratospheric ozone. Geophys. Res. Lett. 25(6):907-10.

16. Jones, A. E., S. Bekki, and J. A. Pyle. 1995. On the atmospheric impact of launching the Ariane 5 rocket. J. Geophys. Res. 100(D8):16651-60.

17. Ross, M., M. Y. Danilin, D. K. Weisenstein, and M. K. W. Ko. 2004. Ozone depletion caused by $\mathrm{NO}$ and $\mathrm{H}_{2} \mathrm{O}$ emissions from hydrazine fueled rockets. J. Geophys. Res. 109(D21305). doi:10.1029/2003JD004370.

18. Ross, M., M. Mills, and D. Toohey. 2010. Potential climate impact of black carbon emitted by rockets. Geophys. Res. Lett. 37(L24810). doi:10.1029/2010GL044548.

19. Siskind, D. E., M.H. Stevens, J. T. Emmert, D. P. Drob, A. J. Kochenash, J. M. Russell, L. L. Gordley, and M. G. Mlynczak. 2003. Signatures of shuttle and rocket exhaust plumes in TIMED/SABER radiance data. Geophys. Res. Lett. 30:1819-23. doi:10.1029/2003GL017627.

20. Stevens, M. H., J. Gumbel, C. R. Englert, K. U. Grossmann, M. Rapp, and P. Hartogh. 2003. Polar mesospheric clouds formed from space shuttle exhaust. Geophys. Res. Lett. 30:1546-50. doi:10.1029/2003GL017249.

21. Stevens, M.H., R.R. Meier, X. Chu, M. T. DeLand, and J. M. C. Plane. 2005. Antarctic mesospheric clouds formed from space shuttle exhaust. Geophys. Res. Lett. 32(L13810). doi:10.1029/2005GL023054.

22. Kelley, M. C., M. J. Nicolls, R.H. Varney, R. L. Collins, R. Doe, J. M. C. Plane, J. Thayer, M. Taylor, B. Thurairajah, and K. Mizutani. 2010. Radar, lidar, and optical observations in the polar summer mesosphere shortly after a space shuttle launch. J. Geophys. Res. 115(A05304). doi:10.1029/2009JA014938.

23. Lübken, F.-J., M. Rapp und I. Strelnikova. 2007. The sensitivity of mesospheric ice layers to atmospheric background temperatures and water vapour. Adv. Space Res. 40:794-801. doi:10.1016/j.asr.2007.01.014. 
24. Jäger, H. 2005. Long term record of lidar observations of the stratospheric aerosol layer at Garmisch Partenkirchen. J. Geophys. Res. 110(D08106). doi:10.1029/2004JD005506.

25. Cziczo, D. J., D. S. Thomson, and D. M. Murphy. 2001. Ablation, flux and atmospheric implications inferred from stratospheric aerosol. Science 291:1772-75.

26. Voigt, C., H. Schlager, B. P. Luo, A. Dörnbrack, A. Roiger, P. Stock, J. Curtius, H. Vössing, S. Borrmann, S. Davies, P. Konopka, C. Schiller, G. Shur, and T. Peter. 2005. Nitric acid trihydrate (NAT) formation at low NAT supersaturation in Polar Stratospheric Clouds (PSCs). Atmos. Chem. Phys. 5(5):11371-80.

27. Paoli, R., D. Cariolle, and R. Sausen. 2011. Review of effective emissions modeling and computation. Geosci. Model Dev. 4:643-67. doi:10.5194/gmd-4-643-2011. 